\title{
Правоприменительная практика: особенности смыслообразования
}

ГАВРИЛОВА Юлия Александровна, доцент кафедры теории и истории права и государства Волгоградского государственного университета, кандидат юридических наук, доцент

400062, Россия, г. Волгоград, Университетский просп., 100

E-mail: gavrilova_ua@volsu.ru

Статья посвящена разработке целостного представления о правоприменительном смыслообразовании, которое является новым понятием юридической науки, отражающим особенности научного познания и анализа прикладных аспектов правоприменительной практики.

Цель исследования - рассмотреть особенности смыслообразования в правоприменительной практике. Задачи исследования - выделить приемы, используемые в правоприменительной практике, и охарактеризовать их в качестве элементов общего понятия правоприменительного смыслообразования, определить их исходное значение и сферу возможного использования, выявить их взаимозависимость для исследования ключевых сторон практики правоприменения, обозначить перспективы развития предложенного направления в теории и практике правового регулирования.

В статье используются формально-юридический, конкретно-социологический и сравнительно-правовой методы.

В правоприменительной практике традиционно определяется состав инструментов, с помощью которых осуществляется решение конкретных юридических дел, вырабатываются ориентиры деятельности правоприменителей и формируется единообразная практика реализации источников права. Теоретические и практические возможности каждого правового средства, используемого в правоприменительной практике, нельзя преувеличивать, так как все они тесно взаимосвязаны.

Однако по своей основной направленности на поиск ситуационного смысла права, составляющего суть правоприменительного смыслообразования, выделяются и рассматриваются как базовые инструменты толкование и конкретизация права в их единстве и взаимосвязи. Они дополняются в случае необходимости с помощью аналогии, субсидиарного правоприменения и других правовых средств, использование которых может объективно и параллельно порождать несвойственные правоприменению результаты деятельности по обновлению и «достраиванию» смысла права. Неоднозначность их доктринальной оценки компенсируется в разной степени их практической ролью: обеспечение стабильности и типичного по логике законодателя направления правоприменительной практики, а также более точного учета изменчивости практики, поддержание социально важных тенденций понимания и применения права. Рассмотрение названных явлений правоприменительной практики в контексте правоприменительного смыслообразования - важнейший путь познания нераскрытых тайн смысла права.

Ключевые слова: правоприменительная практика, смыслообразование, аналогия закона, аналогия права, субсидиарное правоприменение, конкретизация права, толкование права.

\section{Law-Enforcement Practice: Specifics of Meaning-Making}

Yu. A. GAVRILOVA, associate professor at the Volgograd State University, candidate of legal sciences, associate professor

100, Universitetsky ave., Volgograd, Russia, 400062

E-mail: gavrilova_ua@volsu.ru

The problem definition - to elaborate a whole picture of law-enforcement meaning-making, which is a new concept of jurisprudence, reflecting the specifics of scientific knowledge and analysis of the applied aspects of law-enforcement practice.

The purpose of the study is to consider the specifics of meaning-making in law- enforcement practice. Research tasks are to highlight some techniques used in law-enforcement practice, and to characterize them as elements of the general concept of law-enforcement meaning-making, to 
determine their original meaning and the scope of possible use, to reveal their interdependence for research of keyword parties to practice of law-enforcement, to designate prospects of development of proposed direction in the theory and practice of legal regulation.

In the article are used formal legal, specific sociological and comparative legal methods.

In the law-enforcement practice is traditionally defined composition of instruments through which is implemented the solution of specific legal cases, are elaborated rough guides for the activities of law-enforcers and formed a uniform practice of realization of law sources. Theoretical and practical possibilities of each legal tool used in law-enforcement practice, cannot be overstated, as they are all interlinked.

However, its main focus on the search of the situational meaning of the right, the nucleus of the law-enforcement meaning-making, are highlighted and are considered as basic tools the interpretation and concretization of law in their unity and relationship. They are complemented, if necessary, using analogies, subsidiary law-enforcement and other legal instruments, which can objectively and in parallel to generate uncharacteristic for law-enforcement activity results to update and completion meaning of law. The ambiguity of their doctrinal assessment is compensated in varying degrees to their practical role: to ensure a stable and typical for the logic of the legislator the direction of law-enforcement practice, and more accurate account the variability of practice, to support socially important trends in the understanding and application of law. Consideration of all these phenomena of the law-enforcement practice in the context of law-enforcement meaning-making is the most important knowledge way to unsolved mysteries of the meaning of law.

Keywords: law-enforcement practice, meaning-making, analogy of the law, the analogy of law, subsidiary law-enforcement, concretization of law, interpretation of law.

DOI: 10.12737/ art_2018_5_5

Постановка задачи. Обращение к поставленной в статье проблеме продиктовано неисчерпаемостью познания правоприменительной практики и тесно связанных с ней вопросов правовой оценки конкретных обстоятельств дела, преодоления коллизий и пробелов, дискуссионных аспектов интерпретации и конкретизации права. Каждый из указанных феноменов получил самостоятельную и достаточно подробную разработку в отечественном праве, однако до настоящего времени ни один из них еще не рассматривается в рамках единого смыслового измерения права. Между тем все названные явления правоприменительной практики могут быть объединены общим родовым признаком: они представляют собой определенные процедуры и результаты правоприменительного смыслообразования и в этом качестве должны рассматриваться юридической наукой в принципиально новом смысловом ключе.

Обзор научной литературы. Юридическая практика в целом и ее отдельные разновидности в со- ветский период изучались в работах С. Н. Братуся, А. Б. Венгерова, К. М. Гарапшина, В. Н. Карташова, В. И. Леушина, В. П. Реутова ${ }^{1}$. На современном российском этапе исследование практики конституционного правосудия обстоятельно проведено Т. Я. Хабриевой, а правопримени-

${ }^{1}$ См.: Братусъ С. Н. Значение практики Верховного Суда СССР по гражданским делам в охране гражданских правоотношений и в совершенствовании гражданского законодательства // Верховный Суд СССР / под ред. Л. Н. Слирнова, В. В. Куликова, Б. С. Никифорова. М., 1974. С. 205223 ; Венгеров А. Б. Роль судебной практики в развитии советского права: автореф. дис.... канд. юрид. наук. М., 1966; Гарапшин К. М. Правоприменительная практика в советском общенародном государстве: автореф. дис. ... канд. юрид. наук. Казань, 1985; Карташов В. Н. Юридическая деятельность: понятие, структура, ценность. Саратов, 1989; Леушин В. И. Юридическая практика в системе социалистических общественных отношений. Красноярск, 1987; Реутов В. П. Юридическая практика и развитие законодательства: авторефр. дис. ... канд. юрид. наук. Свердловск, 1968. 
тельной практики - Н. Н. Вопленко и А. П. Рожновым ${ }^{2}$. Институт законодательства и сравнительного правоведения при Правительстве Российской Федерации издал актуализированную монографию по проблеме судебной практики ${ }^{3}$. Большинство современных российских правоведов признают судебную практику источником права или отмечают возрастающую тенденцию в этом направлении ${ }^{4}$.

Основная часть. Главная особенность правоприменительного смыслообразования в том, что по организационному оформлению правоприменительная практика существует на двух основных уровнях. Во-первых, рассмотрение и разрешение конкретных юридических дел, где смысл деятельности правоприменителя состоит в дополнении центрального требования законности принципом юридической справедливости, предполагающим максимальное воплощение в решении по делу индивидуальных интересов и коллективных ожиданий его участников. Во-вторых, анализ и обобщение этой практики, на котором долгосрочной целью является оптимальное согласование масштаба и требований общей правовой нормы с конкретными жизненными обстоятельствами, возникающими в сходных фрактических ситуациях. Однако выработать единые доктринальные подходы к такому осмыслению

${ }^{2}$ См.: Хабриева Т. Я. Толкование Конституции Российской Федерации: теория и практика. M., 1998; Вопленко Н. Н., Рожнов А. П. Правоприменительная практика: понятие, основные черты и функции. Волгоград, 2004.

${ }^{3}$ См.: Судебная практика в современной правовой системе России / под ред. Т. Я. Хабриевой, В. В. Лазарева. М., 2017.

${ }^{4}$ См., например: Верещуагин A. Н. Судебное правотворчество в России: сравнительно-правовые аспекты. М., 2004; Витрук Н. В. Конституционное правосудие в России (1991-2001 гг.). М., 2001; Марченко М. Н. Источники права: учеб. пособие. М., 2005. правоприменительной практики достаточно проблематично.

Сложность поиска терминологических конвенций объясняется выбором со стороны ученых в качестве исходного основания какого-либо определенного термина и регулированием сореры его использования. Например, если в качестве базового основания порой выбирается усмотрение, то другие явления правоприменительной практики нередко описываются с помощью разных показателей, характеризующих его степень и пределы (при их наличии): минимального или широкого, интерпретационного, правотворческого усмотрения и т. п. При этом ускользает от внимания принадлежность этих феноменов к арсеналу правоприменительного смыслообразования. Тем не менее сохраняет актуальность задача их более четкого, ясного терминологического разграничения.

В связи со сказанным новое осмысление в современный период времени получает давняя идея В. В. Лазарева о «типичных» и «нетипичных» компонентах правоприменительного процесса ${ }^{5}$. Правоприменение является типичным именно потому, что при разрешении конкретного спора правоприменитель всегда осуществляет поиск «основного» смысла, заложенного законодателем в подлежащие применению нормативные предписания. В этой поисковой направленности правоприменительного смыслообразования и состоит его главная «изюминка». Следовательно, правоприменение будет в той мере нетипично, в какой правоприменитель будет стремиться к уточнению, корректировке действующего нормативного смысла, а иногда и к созданию нового смыслового содержания нормативных предписаний, подчиненного потребностям динамично развивающихся социальных связей и обеспе-

${ }^{5}$ См.: Лазарев В. В. Пробелы в праве и пути их устранения. М., 1974. С. 16, 132. 
ченного с помощью имеющихся организационных возможностей и ресурсов. Это и далее будет нами подразумеваться главным образом по отношению к судебной системе.

В Обзоре судебной практики по делам, связанным с самовольным строительством, утвержденном Президиумом Верховного Суда РФ 19 марта 2014 г., содержится ряд интересных примеров. Исходя из систематического толкования п. 2 ст. 260 и ст. 263 ГК РФ, разъяснено, что при рассмотрении споров о признании права собственности на самовольную постройку помимо доказательств принадлежности истцу земельного участка суду также следует проверять соблюдение его целевого назначения. Это типичное правоприменение.

Однако в другом примере Президиум Верховного Суда РФ пришел к неоднозначному выводу, что приобретательная давность не может распространяться на самовольно возведенное строение, расположенное на неправомерно занимаемом земельном участке, поскольку в подобной ситуации отсутствует признак добросовестности застройщика как необходимое условие приобретения права собственности по этому основанию (ст. 234 ГК РФ). Одновременно на примере еще одного дела разъяснено: суду необходимо проверять, принимало ли лицо все зависящие от него меры по получению разрешения на строительство и (или) акта ввода объекта в эксплуатацию, а также правомерно ли отказал уполномоченный орган в выдаче такого разрешения (акта), что не исключает применение в данном случае положений о добросовестности лица. Как видно, нетипичность правоприменения проявляется в возможности оперирования различными смыслами, часто противоположными по значению, в результате расширения или сужения объема толкования и смысловых пределов действия применяемых правовых норм.
Отсюда правоприменительное смыслообразование имеет сложный двуединый характер и основывается на взаимодействии первоначального смысла нормативного акта, распространяющегося на новые и внешне «стандартные» жизненные случаи, и производных смыслов, полученных при осмыслении в рамках исходного содержания правовых норм, не предусмотренных или недостаточно урегулированных ими фактических ситуаций. Взаимное сочетание элементов типичного и нетипичного в содержании правоприменительных актов свидетельствует о том, что результатом правоприменительного смыслообразования (помимо прецедентов толкования и применения норм права) в концентрированном обобщенном виде являются организационно-вспомогательные правила понимания и применения действующего законодательства, направленные на оптимизацию процессов постижения смысла права. Приоритет их выделения как особого научнопрактического феномена признается в отечественном правоведении за Н. Н. Вопленко ${ }^{6}$.

В процессе правоприменительной практики должностному лицу нередко приходится сталкиваться с явлениями коллизии или конкуренции норм права, когда в поле смыслообразования попадают противоречащие друг другу нормативные предписания или, хотя формально и согласующиеся между собой, но частично пересекающиеся по содержанию или сорере действия. В правотворчестве эти явления устраняются свойственными ему средствами: путем внесения изменений и отмены устаревших положений закона, установлением правил приоритета и т. п. В ходе правоприменения их приходится чаще всего преодолевать с помощью толкования на основе приоритета более позднего по времени, специального или более

${ }^{6}$ См.: Вопленко Н. Н. Официальное толкование норм права. М., 1976. С. 33. 
высокого по юридической силе нормативного акта в однородной сорере общественных отношений. Вопросы предотвращения и разрешения коллизий, конкуренции правовых норм, регулирующих разные сореры общественных отношений, требуют налаживания работы по обеспечению смыслового единства нормативных предписаний и представляют собой специальную законотворческую проблему, поэтому в настоящей статье не освещаются.

При осуществлении деятельности по преодолению пробелов в праве могут конкурировать между собой аналогия закона, аналогия права и субсидиарное правоприменение, которое давно известно отечественному праву ${ }^{7}$. Потребности правоприменительной практики иногда вызывают необходимость в дополнительном параллельном применении к правоотношениям, не урегулированным соответствующими отраслевыми нормами или соглашением сторон, также норм других, смежных отраслей права или применимых к этим отношениям обычаев. Однако вопрос, является субсидиарное правоприменение самостоятельным понятием или особым видом межотраслевой аналогии в праве, длительное время является дискуссионным. Комплексный случай данного взаимодействия содержится в ст. 4 и $5 \mathrm{Ce}-$ мейного кодекса РФ.

Из сопоставления этих статей с п. 1 ст. 6 ГК РФ и ч. 1 ст. 7 З илищного кодекса РФ следует, что общими чертами субсидиарного применения права и аналогии выступают отсутствие необходимого регулирования и соответствие «существу отношений», под которым необходимо понимать сходство по характеру отношений и методам правового регу-

\footnotetext{
${ }^{7}$ См., например: Поленина С. В. Субсидиарное применение норм гражданского законодательства к отношениям смежных отраслей // Советское государство и право. 1967. № 4. C. 28.
}

лирования. Например, применение к личным неимущественным отношениям норм, регулирующих имущественные отношения, не допускается в силу их различного характера. Кроме того, имущественные отношения должны быть построены на одинаковых началах: равенства и автономии воли в гражданском, семейном и жилищном праве.

Однако при разных методах правового воздействия на урегулированные и нерегламентированные отношения субсидиарное применение (или его невозможность) должно быть специально оговорено законом (п. 3 ст. 2 ГК РФ, ч. 2 ст. 4 Водного кодекса РФ).

Приведенные примеры можно излагать и как расширительное толкование норм одной отрасли за счет дополнения сореры их действия с помощью норм другой отрасли. И это еще раз подчеркивает, как важно через правоприменительное смыслообразование снизить «накал страстей» в науке по поводу терминологической «экспансии» одних терминов на предметную область других понятий.

Сложность возникает при разграничении субсидиарного правоприменения и выбора между несколькими разноотраслевыми нормами, подлежащими применению в рамках аналогии закона, с одной стороны, субсидиарного правоприменения и выбора между несколькими разноотраслевыми принципами, подлежащими применению в рамках аналогии права, - с другой. Считаем, что в таких ситуациях «внутри» аналогии речь идет о конкуренции норм и принципов, которая разрешается, во-первых, совместным использованием регуляторов; во-вторых, при невозможности совместного использования - правилами законодательного и доктринального приоритета; в-третьих, при невозможности или отсутствии приоритетов вопрос относится к усмотрению правоприменителя и нуждается в законодательном вмешательстве. 
Из сравнения гражданского, земельного законодательства и законодательства о природных ресурсах выявляется, что в данных кодифицированных актах имеется текстуальное указание на возможность субсидиарного правоприменения. Отсутствие этого указания расценивается в большей степени как несовершенство действующего законодательства, чем как полномочие должностного лица применять право субсидиарно «по умолчанию» или в виде межотраслевой аналогии.

Следовательно, наличие или отсутствие прямого указания в законе является смыслообразующим критерием отличия аналогии закона, аналогии права от субсидиарного правоприменения. Между тем данное указание отсутствует в трудовом законодательстве. Нуждается в дополнении правильная формулировка ст. 15 Трудового кодекса РФ о том, что заключение гражданскоправовых договоров, фрактически регулирующих трудовые отношения между работником и работодателем, не допускается (исходя из «существа отношений»), поскольку субсидиарное применение иных норм гражданского законодательства к некоторым трудовым отношениям возможно и признается большим числом специалистов ${ }^{8}$.

Основные затруднения, возникающие перед исследующими правоприменительную практику учеными, заключаются в проведении слишком жестких границ между толкованием, правоприменением и нормотворчеством, а также в приписывании толкованию свойств «волшебной палочки», один взмах которой рождает новый смысл. Мы исходим из умеренной дифореренциации границ между этими явлениями.

\footnotetext{
${ }^{8}$ Подробнее см.: Лушников А. М., Лушникова М. В. Курс трудового права: учебник: в 2 т. Т. 1: Сущность трудового права и история его развития. Трудовые права в системе прав человека. Общая часть. 2-е изд. М., 2009. С. $449-462$.
}

Данные границы, безусловно, должны существовать, но переходы между ними должны быть гибкими и плавными, что достигается в рамках идеи о правоприменительном смыслообразовании. Однако для его обобщающей характеристики в процессе правоприменительной практики следует отметить особую роль базовых инструментов такого смыслообразования: конкретизации и толкования права.

По вопросу конкретизации права «сломано много копий». Ключевой идеей, которая транслируется в разных исследованиях по этой теме, является представление А. Ф. Черданцева, рассматривавшего конкретизацию как процесс логического выведения (следования) из общих, абстрактных норм права более конкретных, детальных правил поведения, приближенных и предназначенных для регулирования конкретных жизненных отношений, но одновременно не обладающих признаком нормативной новизны ${ }^{9}$.

На основании этого далее сложилось два основных подхода. Одни ученые считают, что конкретизация может существовать и в правотворчестве, и в правоприменении. Другие полагают, что конкретизация может иметь место только в правотворчестве, но не в правоприменении. По нашему мнению, с точки зрения смыслообразования акцент должен делаться не на видах юридической деятельности, а на уровнях и юридических свойствах осуществляемой конкретизации: а) нормативная; б) подзаконная правоориентирующая; в) ситуационная ${ }^{10}$.

Нормативная конкретизация вызывает меньше всего вопросов по поводу ее правотворческой направленности на создание нового смыс-

${ }^{9}$ См.: Черданиеев А. Ф. Вопросы толкования советского права: учеб. пособие. Свердловск, 1972. С. $42-43$.

${ }^{10}$ Об этом см.: Гаврилова Ю. А. Смысл права: вопросы теории и методологии. Волгоград, 2013. С. $235-240$. 
ла норм права. Ситуационная конкретизация направлена на логическое завершение нормативного регулирования в процессе поиска смысла нормы в конкретной правореализационной ситуации, при решении определенного жизненного спора правоприменителем. Следовательно, основное затруднение лежит здесь в научной квалификации тех явлений конкретизации права, которые нельзя однозначно отнести ни к нормативному, ни к ситуационному уровням.

Одним из первых термин «поднормативное регулирование» в 1975 г. употребил С. С. Алексеев ${ }^{11}$. Однако весьма перспективная идея о многослойности регулирования, к сожалению, так и не была развита в достаточно стройную систему понятий. Это, на наш взгляд, породило массу дискуссий на долгие годы, в числе которых место и роль конкретизации в системе понятийного аппарата теории права.

В нашем понимании термин «подзаконное правоориентирующее регулирование» (акты абстрактного нормоконтроля, акты организации и руководства юридической практикой высшими правоприменительными органами) выполняет роль связующего звена по адаптации смысла права между нормативным и ситуационным уровнями с учетом процесса развития общества. Он позволит подчеркнуть подзаконный характер этого регулирования по отношению к нормативному акту и правоориентирующий характер по отношению ко всякой деятельности по реализации права в юридической практике. Его общее правоориентирующее значение для практики не снижается и для тех авторов, которые захотят увидеть в нем конструктивные по характеру элементы нормативной новизны в судебном право-

${ }^{11}$ См.: Алексеев С. С. Структура советского права // Собрание сочинений: в 10 т. T. 2: Специальные вопросы правоведения. M., 2010. C. 97. творчестве, какой бы терминологический дизайн ни придавался этому процессу: «трансорормация», «развитие», «преобразование», «модернизация», «новое прочтение» и др. Во всех названных терминах подразумевается один и тот же френомен конкретизации права.

В юридической литературе последнего времени появились публикации, авторы которых оперируют понятиями «коррекционного» ${ }^{12}$, «восполнительного» ${ }^{13}$, а также «эволютивного» толкования ${ }^{14}$ в качестве аналогов применяемого в зарубежной доктрине «свободного» толкования ${ }^{15}$. Признавая право ученых на существование собственной научной позиции, еще раз выскажем ряд критических замечаний.

Представляется неубедительной точка зрения о том, что распространительное и рестриктивное толкование является способом восполнения пробелов в содержании действующего права. Этимологически и семантически термины «толкование», «коррекция», «восполнение» принадлежат к разным терминосистемам. Толкование - это выяснение, постижение смысла в известных, заранее очерченных рамках. Коррекция означает внесение изменений во что-ли-

${ }^{12}$ См.: Слирнов А. В., Манукян А. Г. Толкование норм права: учеб.-практ. пособие. M., 2008. C. 83-86.

${ }^{13}$ См.: Тихонравов Е. Ю. Понятие расширительного и ограничительного толкования права // Вестник Воронежского государственного университета. Серия: Право. 2016. № 1. С. 90; Байрамкулов А. К. Восполнительное толкование договора на примере мирового соглашения // Закон. 2013. № 2. С. 100.

${ }^{14}$ См.: Аверъянов К. Ю. Решения Европейского суда по правам человека в системе источников права // Актуальные проблемы российского права. 2012. № 2. С. 277278, 284.

${ }^{15}$ См.: Ярославиева Д. К. Метод свободного толкования Конституции в деятельности Верховного суда США // Вестник Вятского государственного гуманитарного университета. 2014. № 3. C. $68-72$. 
бо путем исправления, устранения недостатков. Восполнение - это тоже устранение неполноты, но может включать и добавление в содержание нового, чего ранее не существовало. Более того, приводя норму в соответствие с наибольшей по юридической силе правовой нормой, а иногда и восполняя предполагаемые пробелы, Конституционный Суд РФ выводит собственное новое понимание смысла нормы из системы действующего правового регулирования как из своеобразного «хранилища» смыслов. Кто и как тогда будет определять, что уже было сорормулировано в источниках права, а что не укладывалось в их содержание, кроме самого законодателя?

Приведенные доводы распространяются и на восполнительное толкование положений договора. В соответствии со ст. 431 ГК РФ при невозможности определить содержание договора выясняется действительная общая воля сторон с учетом цели договора. Но цель договора, т. е. то, к чему стороны стремились, исходя из собственных мотивов поведения, охватывает по словарному значению термина действительные и потенциальные намерения сторон.

Вследствие этого теоретическая и практическая необходимость имплементации в российскую цивилистическую доктрину зарубежного института подразумеваемых условий договора (implied terms) представляется спорной, поскольку это может привести к искусственному разделению фактической и правовой сторон, каузы и цели сделки, выступающих в гражданском обороте как единое целое. Изложенное свидетельствует не о восполнительном толковании договора, а о субсидиарном применении к нему других источников: диспозитивных норм, обычаев делового оборота, в том числе lex mercatoria и т. п.

Как верно отмечает А. В. Костикова, «принцип справедливости при толковании предпринимательского договора заключается прежде всего в уважении судом воли сторон, т. е., во-первых, в том, что суд не вправе вмешиваться в соглашение предпринимателей и «исправлять» его, а во-вторых, в возложении рисков и неблагоприятных последствий пробелов и двусмысленности в соглашении на ту сторону, которая имела больший контроль при формулировании спорных условий» ${ }^{16}$. Таким образом, автор, исходя из особенностей российского гражданского оборота, правильно возлагает бремя наступления неблагоприятных последствий толкования на «сильную» сторону в целях защиты прав «слабой» (подчиненной) стороны договора.

В отношении же эволютивных подходов в толковании права, обусловленных эволюцией самого права и потребностью в эфрфективном урегулировании общественных отношений, следует сказать, что по данной проблеме еще в конце XX в.

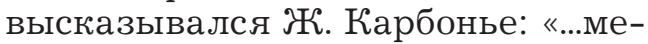
тод исторического или эволюционного толкования... то выдвигался на первый план, то отступал, но всегда имел один и тот же смысл: толкователь должен адаптировать закон к социальным изменениям»17. Взаимосвязь конкретизации права с эфрфективностью правового регулирования отмечалась также Г. Г. Шмелевой: «К общим чертам конкретизации и официального толкования юридических норм можно отнести единство их объекта - нормы права... их объективную необходимость для обеспечения эфрфективного правового регулирования ${ }^{18}$.

Т. Я. Хабриева справедливо отмечает: «Экономически эфрфективное

${ }^{16}$ Костикова А. В. Принцип справедливости при толковании предпринимательского договора // Вестник Санкт-Петербургского университета. Серия 14: Право. 2012. № 4. C. 52.

${ }^{17}$ Карбонъе Ж. Юридическая социология. M., 1986. С. 311.

${ }^{18}$ Шмелева Г. Г. Конкретизация юридических норм в правовом регулировании. Львов, 1988. С. 58. 
законодательство не возникает сразу с применением к праву экономических критериев оценки. Напротив, эфроективность как качество права и законодательства образуется постепенно, в результате осмысления и освоения истории предъявления требований эфрфективности к законодательству и правоприменительной практике» ${ }^{19}$.

В связи со сказанным становится понятно, почему в отечественной доктрине и практике всегда исходили из презумпции, что толкование права само по себе не может создавать нормативную новизну, хотя этот тезис в последние годы вызывает научную дискуссию. В.В.Лазарев пишет: «Естественное право не сорормулировано в качестве четких формализованных установлений. Оно всегда нуждается в законодательном закреплении, в позитивном правотворческом офрормлении. И всякое возведение естественного права в закон является его "конструктивной” интерпретацией и конкретизацией» ${ }^{20}$. Тем не менее толкование по объему может выявлять ценностную и мировоззренческую новизну, которая концептуально достраивается путем нормативных решений в правотворчестве, в результате чего формулируется итоговая смысловая новизна соответствующего правового предписания.

В тех же исключительных случаях, когда толкование по объему особенно в условиях осуществления конституционного (уставного) судопроизводства - фрактически расширяет или сужает смысловые пределы действия норм права, речь должна идти, на наш взгляд, не о восполнительном, эволютивном и т. п. толковании, а о модифицирую-

${ }^{19}$ Хабриева Т. Я. Экономико-правовой анализ: методологический подход // Журнал российского права. 2010. № 12. С. 21.

20 Лазарев В. В. Диалектика объективного и субъективного в интерпретационных актах суда // Журнал российского права. 2017. № 9. С. 100. щем юридическом смыслообразовании, в котором комплексно задействованы возможности не только толкования, но и иных средств правового воздействия: аналогии закона или права, субсидиарного правоприменения и т. д. В ходе дальнейшей правотворческой конкретизации оно трансформируется в юридикоконструктивное смыслообразование, а построение необходимой модели нормативного регулирования общественных отношений находит в этом процессе окончательное логико-юридическое оформление.

Выводы. Цель смыслообразования в правоприменительной практике - практическое воплощение в жизнь защищаемых в нормативных предписаниях ценностей и идей раскрывается в соответствующих задачах: во-первых, достижение максимальной точности и определенности смысла права; во-вторых, дополнительное к законотворческому способу обеспечение единообразного понимания и реализации правовых норм всеми субъектами; в-третьих, определение возможных форм и направлений совершенствования как законодательства, так и самой юридической практики. Базовым инструментарием смыслообразования в правоприменительной практике выступают толкование и конкретизация права в их единстве и взаимосвязи, потенциал которых усиливается в юридической практике по мере необходимости с помощью аналогии, субсидиарного правоприменения и других правовых средств.

Правоприменительная практика - это мир практического бытия и действия права. И чтобы познать этот сложный и непредсказуемый мир, нужно овладеть особого рода искусством. Надеемся, что понятие смыслообразования в правоприменительной практике станет тем «золотым ключиком», который поможет открыть любому человеку «ларец» с множеством тайн и загадок смысла права. 


\section{Библиографический список}

Аверьянов К. Ю. Решения Европейского суда по правам человека в системе источников права // Актуальные проблемы российского права. 2012. № 2.

Алексеев С. С. Структура советского права // Собрание сочинений: в 10 т. Т. 2: Специальные вопросы правоведения. М., 2010.

Байрамкулов А. К. Восполнительное толкование договора на примере мирового соглашения // Закон. 2013. № 2.

Братусь С. Н. Значение практики Верховного Суда СССР по гражданским делам в охране гражданских правоотношений и в совершенствовании гражданского законодательства // Верховный Суд СССР / под ред. Л. Н. Смирнова, В. В. Куликова, Б. С. Никифорова. М., 1974.

Венгеров А. Б. Роль судебной практики в развитии советского права: автореф. дис. ... канд. юрид. наук. М., 1966.

Верещагин А. Н. Судебное правотворчество в России: сравнительно-правовые аспекты. М., 2004.

Витрук Н. В. Конституционное правосудие в России (1991—2001 гг.). М., 2001.

Вопленко Н. Н. Официальное толкование норм права. М., 1976.

Вопленко Н. Н., Рожнов А. П. Правоприменительная практика: понятие, основные черты и функции. Волгоград, 2004.

Гаврилова Ю. А. Смысл права: вопросы теории и методологии. Волгоград, 2013.

Гарапшин К. М. Правоприменительная практика в советском общенародном государстве: автореф. дис. ... канд. юрид. наук. Казань, 1985.

Карбонье Ж. Юридическая социология. М., 1986.

Карташов В. Н. Юридическая деятельность: понятие, структура, ценность. Саратов, 1989.

Костикова А. В. Принцип справедливости при толковании предпринимательского договора // Вестник Санкт-Петербургского университета. Серия 14: Право. 2012. № 4.

Лазарев В. В. Диалектика объективного и субъективного в интерпретационных актах суда // Журнал российского права. 2017. № 9.

Лазарев В. В. Пробелы в праве и пути их устранения. М., 1974.

Леушин В. И. Юридическая практика в системе социалистических общественных отношений. Красноярск, 1987.

Лушников А. М., Лушникова М. В. Курс трудового права: учебник: в 2 т. Т. 1: Сущность трудового права и история его развития. Трудовые права в системе прав человека. Общая часть. 2-е изд. М., 2009.

Марченко М. Н. Источники права: учеб. пособие. М., 2005.

Поленина С. В. Субсидиарное применение норм гражданского законодательства к отношениям смежных отраслей // Советское государство и право. 1967. № 4.

Реутов В. П. Юридическая практика и развитие законодательства: автореф. дис. ... канд. юрид. наук. Свердловск, 1968.

Смирнов А. В., Манукян А. Г. Толкование норм права: учеб.-практ. пособие. М., 2008.

Судебная практика в современной правовой системе России / под ред. Т. Я. Хабриевой, В. В. Лазарева. М., 2017.

Тихонравов Е. Ю. Понятие расширительного и ограничительного толкования права // Вестник Воронежского государственного университета. Серия: Право. 2016. № 1.

Хабриева Т. Я. Толкование Конституции Российской Федерации: теория и практика. M., 1998.

Хабриева Т. Я. Экономико-правовой анализ: методологический подход // Журнал российского права. 2010. № 12.

Черданцев А. Ф. Вопросы толкования советского права: учеб. пособие. Свердловск, 1972.

Шмелева Г. Г. Конкретизация юридических норм в правовом регулировании. Львов, 1988.

Ярославцева Д. К. Метод свободного толкования Конституции в деятельности Верховного суда США // Вестник Вятского государственного гуманитарного университета. 2014. № 3. 